\title{
A Test of the Predictive Validity of Animal Models of Schizophrenia Based on Phencyclidine and D-Amphetamine
}

Frank Sams-Dodd, Ph.D.

Antipsychotic drugs can inhibit the effects of phencyclidine $(P C P)$ and d-amphetamine (AMPH) in many rodent tests, but the effects are usually seen at doses that also affect vehicle-treated control rats, suggesting that the inhibition may be nonspecific. This study will attempt to test the predictive validity of these models based on the clinical observations that antipsychotics are not fully effective until after 2-3 weeks of administration in patients and that patients do not relapse immediately following abrupt withdrawal of medication. Haloperidol and clozapine were tested in rats after daily administration for 3 and 21 days in combination with vehicle or PCP $(2.0 \mathrm{mg} / \mathrm{kg})$ in the social interaction test, and with vehicle or AMPH $(0.5 \mathrm{mg} / \mathrm{kg})$ in standard activity cages. To separate acute from more longlasting effects on the central nervous system (CNS) haloperidol and clozapine were tested with a short (45 or 30 min depending upon test) and a long (22-24 h) pretreatment time. The results demonstrated that haloperidol and clozapine following both 3 and 21 days of administration at the short pretreatment time inhibited the activity of vehicle-, $P C P_{-}$, and $A M P H$-treated rats, whereas neither drug had consistent effects in any group at the long pre-treatment time. The data suggest that antipsychotics only inhibit $P C P$-and AMPH-induced behaviors in rodents by an acute drug-drug interaction, whereas any long-term effects of antipsychotic drug administration on the CNS cannot be revealed by $P C P$ and $A M P H$ in rodents.

[Neuropsychopharmacology 18:293-304, 1998]

(C) 1998 American College of Neuropsychopharmacology Published by Elsevier Science Inc.
KEY WORDS: Amphetamine; Negative symptoms; Antipsychotics; Phencyclidine; Positive symptoms; Rat; Schizophrenia

A number of animal models of schizophrenia are based on the empirical observation that phencyclidine (PCP) and d-amphetamine (AMPH) can induce a model psychosis in human volunteers that resemble an acute schizophrenic episode (Connell 1958; Siegel 1978). In rats, both compounds induce behavioral changes that include locomotor hyperactivity, stereotyped behavior, and social withdrawal (Murray and Horita 1979; Robinson and

From Pharmacological Research, Valby, Denmark.

Address correspondence to: Dr. Frank Sams-Dodd, Pharmacological Research, H. Lundbeck A/S, Ottiliavej 9, DK-2500 Valby, Denmark.

Received June 13, 1997; revised August 11, 1997; accepted August 18,1997
Becker 1986; Sams-Dodd 1995a) that can be inhibited by acute and chronic administration of antipsychotic drugs (Jackson et al. 1994; Arnt 1995; Sams-Dodd 1996, 1997). Thus, it has been suggested that these models have predictive validity. However, the antipsychotics often inhibit the behavior of vehicle-treated control rats at the same doses at which they affect the PCP- and AMPHinduced behaviors. This suggests that part of the effect of the antipsychotic drugs on the PCP- and AMPHinduced behaviors may be nonspecific.

Classical and atypical antipsychotic drugs do not reach their full antipsychotic potential in schizophrenic patients until after 2-3 weeks or more of administration (Freed 1988). Following abrupt withdrawal of oral haloperidol or a comparable neuroleptic drug Viguera et al. (1997) have found that the average relapse-rate is $1.7 \%$ per week for the first 30 weeks. Haloperidol has a mean 
plasma half-life of approximately $20 \mathrm{~h}$ in humans (Khot et al. 1993) and there is therefore not a direct correlation between plasma level and time to relapse. For clozapine the relapse in some patients tends to occur within 1 week following withdrawal of medication, whereas others do not show any changes in psychopathology for up to 2 weeks (Borison et al. 1988). The plasma half-life of clozapine ranges from 9 to $17 \mathrm{~h}$ in humans (Jann et al. 1993; Lin et al. 1994), and the effect of clozapine on psychopathology therefore appears to be closely correlated to its plasma level in some patients, whereas it in others is comparable to classical neuroleptics.

In rats the half-life is only $1.5 \mathrm{~h}$ for haloperidol and clozapine (Cheng and Paalzow 1992; Baldessarini et al. 1993), but in spite of these species differences in pharmacokinetics several studies have found using physiological parameters that rats probably show a temporal response to antipsychotic drug treatment that is comparable to humans (e.g. Bunny and Grace 1978; Vahid-Ansari et al. 1996). It should therefore be possible to measure a specific dose-dependent reduction in the PCP- and AMPHinduced behaviors after long-term administration of an antipsychotic drug at $24 \mathrm{~h}$ after the last drug administration, since most of the acute effects and side effects (i.e., motor disturbances) will have disappeared at this time point while the antipsychotic effect should be retained. Based on these findings, it should be possible to determine the predictive validity of models of schizophrenia based on PCP and AMPH without the interference of side effects.

Haloperidol and clozapine are tested in rats after short(3 days) and long-term (21 days) administration and after a short (30-45 $\mathrm{min})$ and a long (22-24 h) pretreatment time in behavioral tests sensitive to PCP and AMPH. For PCP the experiments are conducted in the social interaction test where PCP induces stereotyped behavior and social isolation (Sams-Dodd 1996), and for AMPH in standard activity cages, where AMPH induces locomotor hyperactivity (Jackson et al. 1994). The effects of a short pretreatment time of $45 \mathrm{~min}$ for haloperidol and clozapine on PCP-induced behaviors have previously been described and will not be repeated (Sams-Dodd 1996).

\section{MATERIALS AND METHODS}

\section{Animals}

Male Wistar rats (Charles River, Germany) weighing $320-420 \mathrm{~g}$ at the time of testing were used for these experiments. They were housed in groups of three in Macrolon type III cages in an animal room at $21 \pm 2{ }^{\circ} \mathrm{C}$ with a relative humidity of $55 \pm 5 \%$, air exchange (16 times/h) and kept in a reversed 12-h light-dark cycle (light on $18.00 \mathrm{~h}-06.00 \mathrm{~h}$ ). They had free access to water and commercial food pellets throughout the study.

\section{Drugs}

Phencyclidine (N-(l-phenylcyclohexyl)piperidine, hydrochloride; mol. wt. 280.5; synthesized at H. Lundbeck $\mathrm{A} / \mathrm{S}$ ) and d-amphetamine sulphate (d-amphetamine $1 / 2$ sulphate; mol. wt. 184.3; Nomeco, Copenhagen) were dissolved in $0.9 \% \mathrm{NaCl}$ solution. Haloperidol (mol. wt. 375.9; Janssen) and clozapine (mol. wt. 327; Sandoz, s.a.) were dissolved in minimal amounts of acid, diluted with saline and $\mathrm{pH}$ adjusted. Vehicle solution was $0.9 \% \mathrm{NaCl}$. For all experiments the solutions were filtered with a Millix-HA filter (0.45 $\mu \mathrm{m}$; Millipore Corp).

\section{Experimental Procedures}

After arrival the rats were randomly assigned to groups of three and were placed in a reversed light cycle for 3.5 weeks. The rats were housed with the same cage mates at all times and all rats within a given cage received identical treatment. The rats received daily injections in their home cage for 3 days and 21 days, respectively of vehicle, haloperidol, or clozapine and were tested on the day of the last injection after the appropriate pretreatment period had expired. The first day of drug administration was chosen such that all the rats were tested approximately 3.5 weeks after their arrival. All experiments for a given drug were repeated to ensure replicability and the rats were never tested more than once.

For the social interaction test half of the rats within a treatment paradigm were dyed with hair color 2 weeks after arrival and during the following week all the rats were tested in the social interaction test. Testing was conducted over a 2-day period. In addition to the antipsychotic drugs, the rats also received for the last 3 days of the antipsychotic drug administration regimen either vehicle or $7.1 \mu \mathrm{mol} / \mathrm{kg}$ of PCP $(2.0 \mathrm{mg} / \mathrm{kg})$. Each treatment group included six pairs of rats per experiment. The pretreatment times were either $45 \mathrm{~min}$ or $22-24 \mathrm{~h}$ for the antipsychotic drug administration regimen, i.e., vehicle, haloperidol, and clozapine, and $45 \mathrm{~min}$ for vehicle and PCP.

For the motility test the rats received in combination with the antipsychotic drug administration regime either vehicle or $2.7 \mu \mathrm{mol} / \mathrm{kg}$ of AMPH $(0.5 \mathrm{mg} / \mathrm{kg})$ on the last day of the antipsychotic drug administration regime. Each treatment group included six rats per experiment. The pretreatment times were either $30 \mathrm{~min}$ or $22-24 \mathrm{~h}$ for the antipsychotic drug administration regime, i.e., vehicle, haloperidol, and clozapine, and $0 \mathrm{~min}$ for vehicle and AMPH.

\section{Social Interaction Test}

The general design of the model was adapted from File (1980) and has previously been described in detail (Sams-Dodd 1995b, 1996). The test was performed in an open arena $(\mathrm{l}, \mathrm{w}, \mathrm{h}: 150 \mathrm{~cm} \times 100 \mathrm{~cm} \times 40 \mathrm{~cm})$ with bed- 
ding of gray gravel. The gravel had been exposed to other rats before testing to provide a constant odor level in the arena. The behavior of the rats was recorded by a video camera (Cohou model 4722-2000 with Ernitec 6 $\mathrm{mm} / 1.2$ lens) that was placed above the arena and was connected to a S-VHS video cassette recorder. Lighting in the room consisted only of dark-red light (25 Watt bulbs) and was diffused to minimize shadows in the arena. Three arenas were run in parallel and were started at the same time.

The white and black rats were placed in the experimental room the day before testing. On the day of testing all rats were weighed. One white and one black rat, that had received identical treatment and that were unfamiliar to each other, were placed simultaneously into the unfamiliar arena $80-90 \mathrm{~cm}$ apart. Their behavior was video filmed for $10 \mathrm{~min}$ whereafter the rats were returned to their home cages. Testing in the social interaction test was conducted between $8: 00 \mathrm{~h}$ and $14.00 \mathrm{~h}$.

First, each 10-min observation period on the videotapes was analyzed off-line by the EthoVision ${ }^{\circledR}$ program (version 1.80, Noldus Information Technologies, b.v.). The arena was scanned 3.1 times per s by the program and for each scanning the positions of the rats were determined. These coordinates were subsequently related to actual distances in the arena by a calibration of the program to the dimensions of the arena. This analysis resulted in a track record for each rat that contained a complete record of the rat's movement pattern in the arena during the observation period and this track record was analyzed for the following parameters:

Distance traveled $(\mathrm{cm})$ : Total distance traveled during an observation period.

Percent time in central zone: Percentage of the 10-min observation period spend in the central zone by each rat. The arena was divided into a central and a peripheral zone that covered $33 \%$ and $66 \%$ of the arena, respectively.

Active and passive social interaction (s): Social interaction was defined as a maximal distance of $20 \mathrm{~cm}$ between the rats, and it was subsequently divided into an active and a passive component for each rat based upon whether the rat actively moved or was inactive (for a detailed description of this parameter, see SamsDodd 1996).

Secondly, each observation was rated for stereotyped behavior by a trained observer, who was blind to the treatment paradigm. Each recording on the videotapes was viewed for $60 \mathrm{~s}$ halfway through the 10-min observation period, and each rat was given a score for PCP stereotyped behaviour. The score assigned was determined as the highest level of stereotypy consistently observed during the rating period. The rating scale is given below and is after Castellani and Adams (1981).
PCP stereotyped behavior: (0) Stationary, little or no movement; (1) Active, occasional to frequent movement; (2) Active with episodes of repetitive forward head searching (the rat walked forward in a stereotyped manner along the periphery of the arena without engaging in other behaviors); (3) Continuous forward searching; (4) Frequent repetitive rearing, side-to-side weaving or turning; (5) Episodes of rapid jerky side-toside, circular or dorso-ventral head movements (the rat was usually stationary).

\section{Motility Test}

Locomotor activity was measured for $120 \mathrm{~min}$ in Macrolon type III $(\mathrm{l}, \mathrm{w}, \mathrm{h}: 37 \mathrm{~cm} \times 22 \mathrm{~cm} \times 19 \mathrm{~cm})$ animal cages with a bedding of wood shavings in a brightly lit room. Four sets of equally spaced photo diodes registered movements in the longitudinal direction of individual cages as the number of times the infrared light beams were interrupted. The activity counts would not increment if the same light beam was interrupted twice or more in a row without activation of other beams, thus preventing repetitive stationary movements from affecting the activity counts. Registration and timing of locomotor activity was fully automated (custom-designed hardware and software).

\section{Data and Statistical Analysis}

Two-way ANOVA with Fishers LSD post hoc test was used (two-tailed) for statistical analysis of all the behavioral parameters. The stereotypy scores, which are of an ordinal type, were ranked (Huitema 1980) and the activity counts from the motility test were log-transformed prior to statistical analysis. All data are presented as means with standard error of mean (SEM) and the statistical analysis was performed with Systat v. 5.2 (Macintosh version).

\section{RESULTS}

\section{Social Interaction Test}

After placement in the arena, the vehicle-treated control rats made an initial inspection of the arena and each other, whereafter they moved around together to explore the novel area and interacted frequently. In contrast the PCP-treated control rats that had received a standard dose of $7.1 \mu \mathrm{mol} / \mathrm{kg}(2.0 \mathrm{mg} / \mathrm{kg})$ walked, often continuously, along the periphery of the arena in a stereotyped manner and avoided or ignored the unfamiliar rat, and they consistently displayed increased levels of distance traveled and PCP stereotyped behavior and decreased levels of active social interaction and percent time in central zone (Figures 1-4 to the left of the broken dose-axis). Statistical comparison between 
the vehicle/vehicle- and the vehicle/PCP-treated control rats demonstrated significant differences between them in all experiments as seen in Table 1 where the statistical results for the social interaction tests have been summarized.

Short-term administration of haloperidol (0.1-3.4 $\mu \mathrm{mol} / \mathrm{kg} ; 0.04-1.28 \mathrm{mg} / \mathrm{kg}$ ) in combination with vehicle or PCP for 3 days with a pretreatment time of 22-24 $\mathrm{h}$ for haloperidol and $45 \mathrm{~min}$ for PCP had very limited effects on the behavior of the rats (Figure 1). In the vehicle-treated rats haloperidol caused a significant decrease in active social interaction at the highest dose, but did not affect the locomotor activity, stereotypy score or per cent time in central zone, which indicate that the explorative behaviors were unaffected by haloperidol at the long pretreatment time. In the PCPtreated rats haloperidol induced a dose-dependent inhibition of the locomotor hyperactivity for doses of 1.7 $\mu \mathrm{mol} / \mathrm{kg}$ and upward, but without affecting percent time in central zone or the stereotyped behavior. In addition, haloperidol did not alleviate the PCP-induced deficits in active social interaction. There was a small, but significant increase in passive social interaction in the PCP-treated rats at the highest dose of haloperidol, but the overall level of social interaction did not return to the level of vehicle-treated control rats.
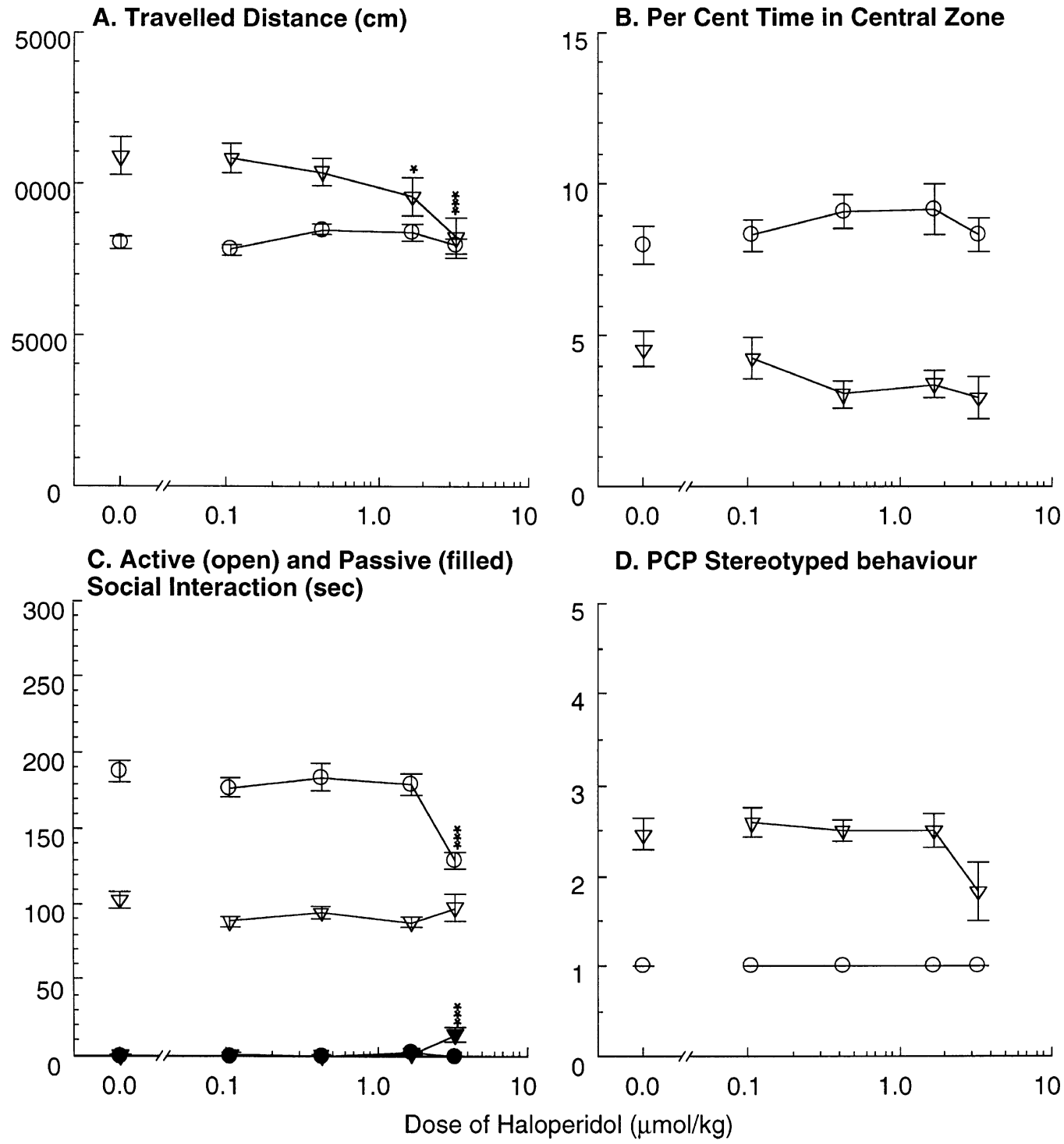

Figure 1. Dose-response of haloperidol in combination with either vehicle or $7.1 \mu \mathrm{mol} / \mathrm{kg}$ of PCP following daily SC administration for 3 days. The rats were tested in the social interaction test and pretreatment time was 22-24 h for haloperidol and $45 \mathrm{~min}$ for PCP. Each treatment group includes 12 pairs of rats. Symbols: $(\bigcirc)$ Haloperidol in combination with vehicle; $(\nabla)$ Haloperidol in combination with $7.1 \mu \mathrm{mol} / \mathrm{kg}$ of PCP. Asterisks indicate level of significance based on a Fisher's LSD post hoc test and are relative to the control group of that particular administration regime. ${ }^{*} p<.05 ;{ }^{* *} p<.01 ;{ }^{* * *} p<.001$. 

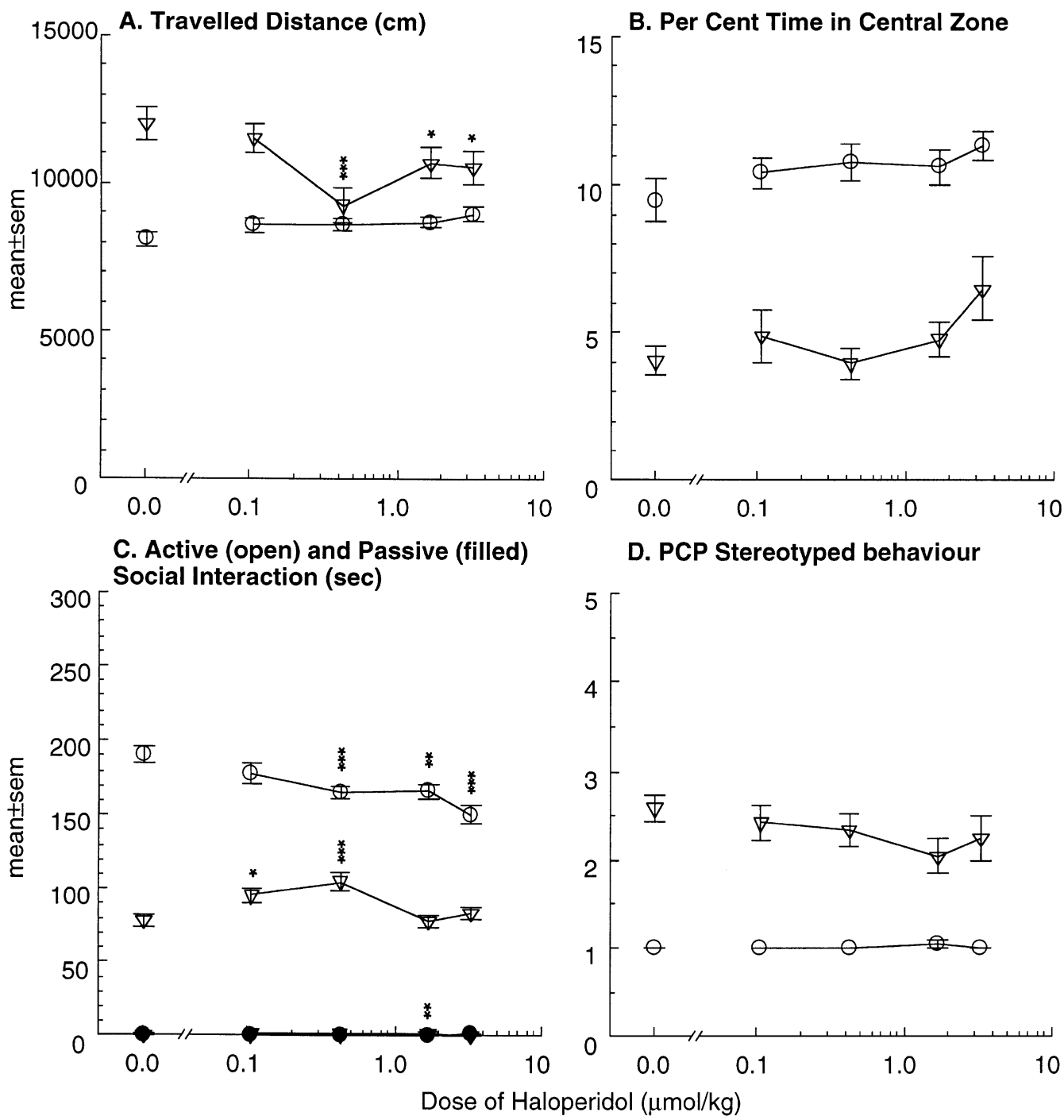

Figure 2. Dose-response of haloperidol following daily SC treatment for 21 days in combination with either vehicle or 7.1 $\mu \mathrm{mol} / \mathrm{kg}$ of PCP during the final 3 days of the haloperidol treatment regime. The rats were tested in the social interaction test and pretreatment time was 22-24 h for haloperidol and $45 \mathrm{~min}$ for PCP. Each treatment group includes 12 pairs of rats. Symbols: $(\bigcirc)$ Haloperidol in combination with vehicle; $(\nabla)$ Haloperidol in combination with $7.1 \mu \mathrm{mol} / \mathrm{kg}$ of PCP. See Figure 1 for explanation of asterisks.

The effects of long-term administration of haloperi$\mathrm{dol}(0.1-3.4 \mu \mathrm{mol} / \mathrm{kg} ; 0.04-1.28 \mathrm{mg} / \mathrm{kg})$ for 21 days in combination with vehicle or PCP during the last 3 days of the haloperidol administration regimen using a pretreatment time of 22-24 h for haloperidol and $45 \mathrm{~min}$ for PCP is shown in Figure 2. In the vehicle-treated rats haloperidol caused a slight, but significant dose-dependent decrease in active social interaction from $0.4 \mu \mathrm{mol} / \mathrm{kg}$ and upward, but did not affect the locomotor activity, stereotypy score or percent time in central zone, which indicate that the explorative behaviors of the vehicletreated rats were unaffected by haloperidol. In the PCPtreated rats, haloperidol induced an inhibition of the locomotor hyperactivity from $0.4 \mu \mathrm{mol} / \mathrm{kg}$ and upward, but without affecting percent time in central zone or the stereotyped behavior. Haloperidol had a slight alleviating effect on the PCP-induced deficits in active social interaction at 0.1 and $0.4 \mu \mathrm{mol} / \mathrm{kg}$, but this effect disappeared at higher doses. Finally, haloperidol caused a slight increase in passive social interaction, but this effect was too small to be considered of relevance.

Short-term administration of clozapine $(0.5-7.6 \mu \mathrm{mol} /$ $\mathrm{kg}$; $0.16-2.5 \mathrm{mg} / \mathrm{kg}$ ) in combination with vehicle or PCP for 3 days with a pretreatment time of 22-24 h for clozapine and $45 \mathrm{~min}$ for PCP had, like haloperidol, very limited effects on the behavior of the rats (Figure 3). In the vehicle-treated rats, clozapine did not have any effects on their behavior. In the PCP-treated rats, clozapine induced a dose-dependent reduction of the locomotor hyperactivity at 1.9 and $7.6 \mu \mathrm{mol} / \mathrm{kg}$, but also augmented the stereo- 

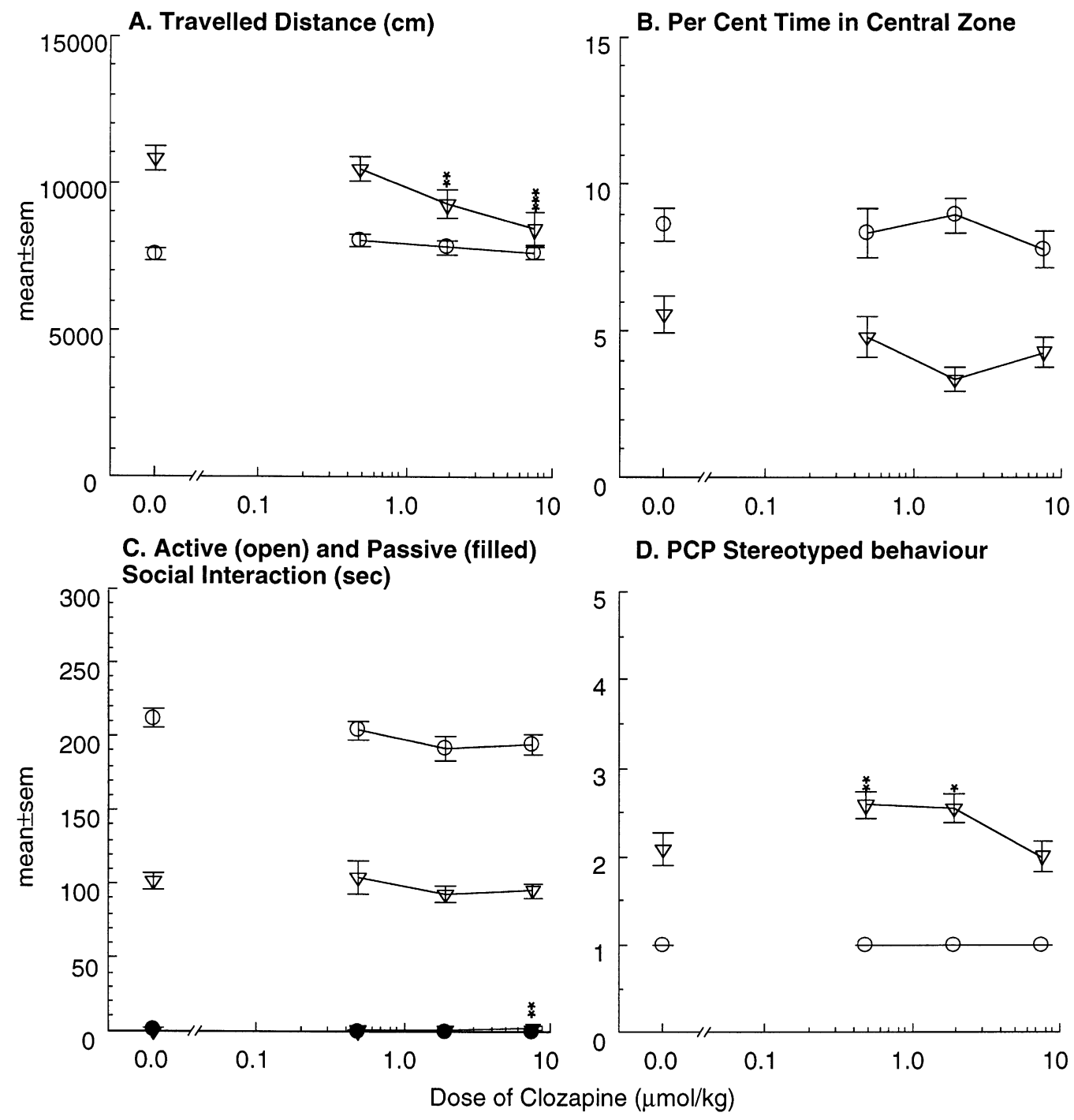

Figure 3. Dose-response of clozapine in combination with either vehicle or $7.1 \mu \mathrm{mol} / \mathrm{kg}$ of PCP following daily SC administration for 3 days. The rats were tested in the social interaction test and pretreatment time was 22-24 h for clozapine and 45 min for PCP. Each treatment group includes 12 pairs of rats. Symbols: $(\bigcirc)$ Clozapine in combination with vehicle; $(\nabla)$ Clozapine in combination with $7.1 \mu \mathrm{mol} / \mathrm{kg}$ of PCP. See Figure 1 for explanation of asterisks.

typed behavior slightly at 0.5 and $1.9 \mu \mathrm{mol} / \mathrm{kg}$. Clozapine did not alleviate the stereotyped behavior at any of the doses tested. In addition clozapine did not affect the PCP-induced changes in percent time in central zone and did not affect the deficits in social interaction.

The effects of long-term administration of clozapine $(0.12-7.6 \mu \mathrm{mol} / \mathrm{kg}$; $0.04-2.5 \mathrm{mg} / \mathrm{kg})$ for 21 days in combination with vehicle or PCP for the last 3 days of the clozapine administration regimen and using a pretreatment time of $22-24 \mathrm{~h}$ for clozapine and $45 \mathrm{~min}$ for PCP is shown in Figure 4. In the vehicle-treated rats, clozapine caused a slight, but significant increase in active social interaction and a reduction in percent time in central zone at the lowest dose of $0.12 \mu \mathrm{mol} / \mathrm{kg}$, but these effects disappeared at the higher doses, and from $0.5 \mu \mathrm{mol} / \mathrm{kg}$ and up- ward clozapine did not affect the behavior of the vehicletreated rats. In the PCP-treated rats clozapine did not affect the locomotor hyperactivity, but at a single dose of $0.5 \mu \mathrm{mol} / \mathrm{kg}$ clozapine partially reversed the effects of PCP on percent time in central zone and partially normalized the stereotyped behavior. Clozapine also induced a slight increase in the active social interaction toward vehicle-control levels, but only at 0.12 and $1.9 \mu \mathrm{mol} / \mathrm{kg}$. Clozapine did not affect passive social interaction.

\section{Motility Test}

AMPH at a standard dose of $0.5 \mathrm{mg} / \mathrm{kg}$ reliably induces locomotor hyperactivity in rats and a significant difference in locomotor activity between vehicle- and AMPH- 

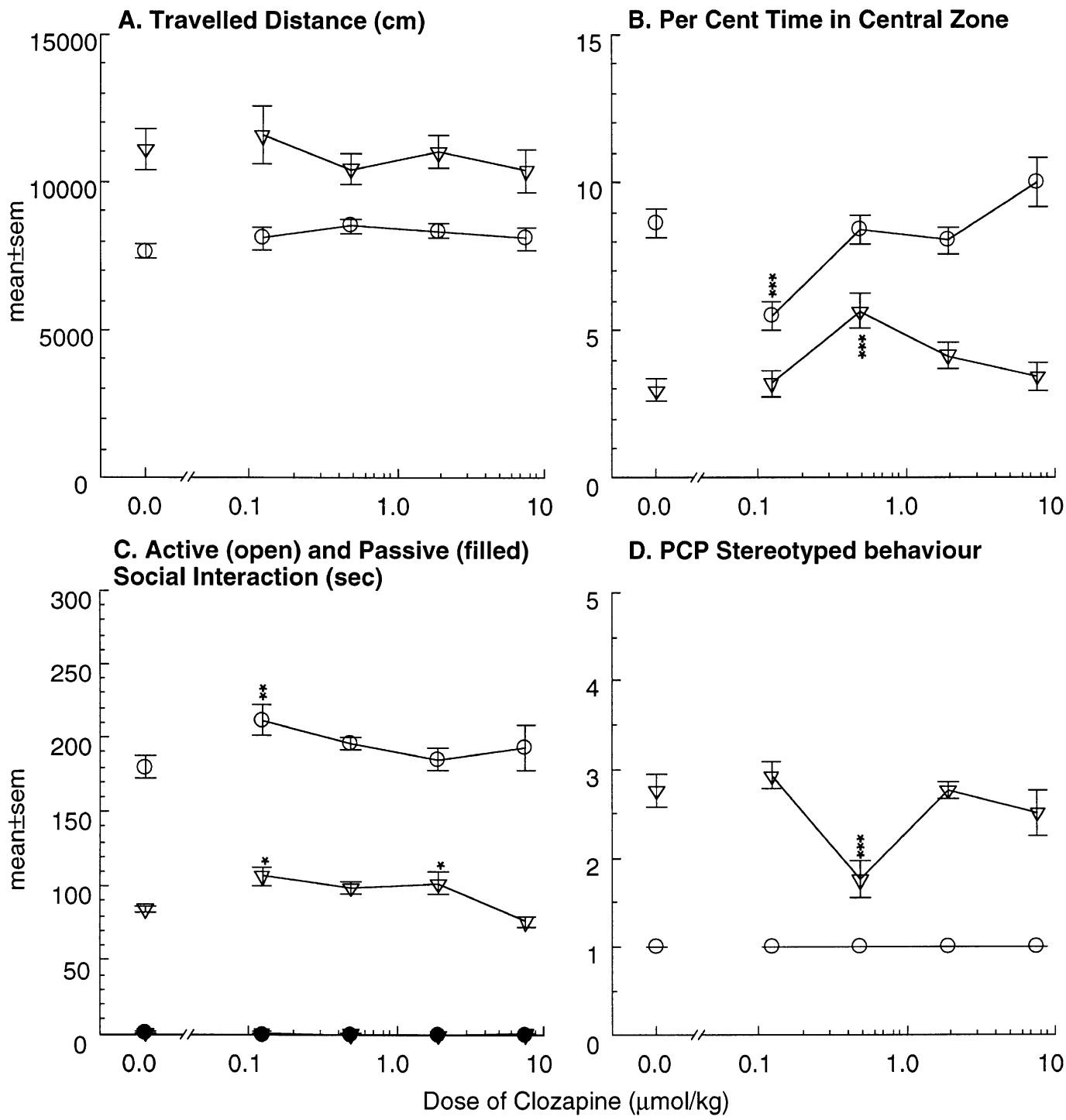

Figure 4. Dose-response of clozapine following daily SC treatment for 21 days in combination with either vehicle or 7.1 $\mu \mathrm{mol} / \mathrm{kg}$ of PCP during the final 3 days of the clozapine treatment regime. The rats were tested in the social interaction test and pretreatment time was 22-24 h for clozapine and $45 \mathrm{~min}$ for PCP. Each treatment group includes 12 pairs of rats. Symbols: $(\bigcirc)$ Clozapine in combination with vehicle; $(\nabla)$ Clozapine in combination with $7.1 \mu \mathrm{mol} / \mathrm{kg}$ of PCP. See Figure 1 for explanation of asterisks.

treated rats was observed in all experiments. The effects of short- and long-term administration of haloperidol and clozapine daily for 3 and 21 days, respectively, in combination with vehicle or $2.7 \mu \mathrm{mol} / \mathrm{kg}$ of AMPH on the last day of antipsychotic drug administration is shown in Figures 5 and 6. In addition to 3 and 21 days of administration of the antipsychotic drugs, haloperidol and clozapine were also tested after a pretreatment time of $30 \mathrm{~min}$ and of $22-24 \mathrm{~h}$, whereas the pretreatment time always was 0 min for AMPH.

Short-term administration of haloperidol ( 0.4 and 1.7 $\mu \mathrm{mol} / \mathrm{kg}$; 0.16 and $0.64 \mathrm{mg} / \mathrm{kg}$ ) (Figure 5A) with a pretreatment time of $30 \mathrm{~min}$ for haloperidol produced a significant reduction in the locomotor activity of both vehicle- and AMPH-treated rats (dose: $\mathrm{F}(2,78)=203.0$; $p<.001$; treatment $\mathrm{F}(1,78)=51.5 ; p<.001$; dose $\times$ treatment $\mathrm{F}(2,78)=5.8 ; p<.01)$, whereas haloperidol at the long pretreatment time did not have any effects in the vehicle- or AMPH-treated rats, although there was a tendency towards a slight increase in the AMPH-induced hyperactivity at the highest dose (dose: $\mathrm{F}(2,69)=0.8$; $p=\mathrm{NS}$; treatment $\mathrm{F}(1,69)=184.0 ; p<.001$; dose $\times$ treatment $\mathrm{F}(2,69)=2.1 ; p=\mathrm{NS})$. After long-term administration (Figure 5B) haloperidol at the short pretreatment time produced a significant reduction in the locomotor activity of both vehicle- and AMPH-treated rats (dose: $\mathrm{F}(2,66)=98.9 ; p<.001$; treatment $\mathrm{F}(1,66)=$ 68.7; $p<.001$; dose $\times$ treatment $\mathrm{F}(2,66)=3.6 ; p<.05)$. 
Table 1. Summary of the Statistical Results of the Effects of Haloperidol and Clozapine on PCP-Induced Behaviors in the Social Interaction Test

\begin{tabular}{|c|c|c|c|c|c|}
\hline Social Interaction Test & Distance Traveled & $\begin{array}{l}\text { Percent Time in } \\
\text { Central Zone }\end{array}$ & $\begin{array}{l}\text { Active Social } \\
\text { Interaction }\end{array}$ & $\begin{array}{l}\text { Passive Social } \\
\text { Interaction }\end{array}$ & $\begin{array}{c}\text { PCP Stereotyped } \\
\text { Behavior }\end{array}$ \\
\hline \multicolumn{6}{|l|}{ Haloperidol } \\
\hline \multicolumn{6}{|l|}{ Short-term } \\
\hline$(d f=4,206):$ dose & $\mathrm{F}=2.3 ; p=\mathrm{NS}$ & $\mathrm{F}=0.3 ; p=\mathrm{NS}$ & $\mathrm{F}=4.9 ; p<0.01$ & $\mathrm{~F}=8.8 ; p<0.001$ & $\mathrm{~F}=1.9 ; p=\mathrm{NS}$ \\
\hline Treatment & $\mathrm{F}=40.8 ; p<0.001$ & $\mathrm{~F}=146.3 ; p<0.001$ & $\mathrm{~F}=340.0 ; p<0.001$ & $\mathrm{~F}=19.4 ; p<0.01$ & $\mathrm{~F}=311.3 ; p<0.001$ \\
\hline Dose $\times$ treatment & $\mathrm{F}=2.8 ; p<0.05$ & $\mathrm{~F}=1.8 ; p=\mathrm{NS}$ & $\mathrm{F}=5.1 ; p<0.001$ & $\mathrm{~F}=9.9 ; p<0.001$ & $\mathrm{~F}=1.9 ; p=\mathrm{NS}$ \\
\hline \multicolumn{6}{|l|}{ Long-term } \\
\hline$(d f=4,206):$ dose & $\mathrm{F}=2.6 ; p<0.05$ & $\mathrm{~F}=2.0 ; p=\mathrm{NS}$ & $\mathrm{F}=4.6 ; p<0.01$ & $\mathrm{~F}=0.2 ; p=\mathrm{NS}$ & $\mathrm{F}=0.9 ; p=\mathrm{NS}$ \\
\hline Treatment & $\mathrm{F}=62.5 ; p<0.001$ & $\mathrm{~F}=170.8 ; p<0.001$ & $\mathrm{~F}=550.7 ; p<0.001$ & $\mathrm{~F}=2.3 ; p=\mathrm{NS}$ & $\mathrm{F}=262.4 ; p<0.001$ \\
\hline Dose $\times$ treatment & $\mathrm{F}=4.6 ; p<0.01$ & $\mathrm{~F}=0.5 ; p=\mathrm{NS}$ & $\mathrm{F}=7.4 ; p<0.001$ & $\mathrm{~F}=2.6 ; p<0.05$ & $\mathrm{~F}=1.3 ; p=\mathrm{NS}$ \\
\hline \multicolumn{6}{|l|}{ Clozapine } \\
\hline \multicolumn{6}{|l|}{ Short-term } \\
\hline$(d f=3,180):$ dose & $\mathrm{F}=4.9 ; p<0.01$ & $\mathrm{~F}=1.2 ; p=\mathrm{NS}$ & $\mathrm{F}=1.9 ; p=\mathrm{NS}$ & $\mathrm{F}=1.3 ; p=\mathrm{NS}$ & $\mathrm{F}=2.7 ; p<0.05$ \\
\hline Treatment & $\mathrm{F}=57.3 ; p<0.001$ & $\mathrm{~F}=81.4 ; p<0.001$ & $\mathrm{~F}=425.8 ; p<0.001$ & $\mathrm{~F}=0.9 ; p=\mathrm{NS}$ & $\mathrm{F}=266.9 ; p<0.001$ \\
\hline Dose $\times$ treatment & $\mathrm{F}=4.2 ; p<0.01$ & $\mathrm{~F}=1.7 ; p=\mathrm{NS}$ & $\mathrm{F}=0.3 ; p=\mathrm{NS}$ & $\mathrm{F}=3.0 ; p<0.05$ & $\mathrm{~F}=2.7 ; p<0.05$ \\
\hline \multicolumn{6}{|l|}{ Long-term } \\
\hline$(d f=5,250):$ dose & $\mathrm{F}=0.3 ; p=\mathrm{NS}$ & $\mathrm{F}=6.1 ; p<0.001$ & $\mathrm{~F}=3.9 ; p<0.01$ & $\mathrm{~F}=1.9 ; p=\mathrm{NS}$ & $\mathrm{F}=7.5 ; p<0.001$ \\
\hline Treatment & $\mathrm{F}=65.7 ; p<0.001$ & $\mathrm{~F}=145.9 ; p<0.001$ & $\mathrm{~F}=458.8 ; p<0.001$ & $\mathrm{~F}=2.8 ; p=\mathrm{NS}$ & $\mathrm{F}=361.1 ; p<0.001$ \\
\hline Dose $\times$ treatment & $\mathrm{F}=1.0 ; p=\mathrm{NS}$ & $\mathrm{F}=5.1 ; p<0.001$ & $\mathrm{~F}=1.4 ; p=\mathrm{NS}$ & $\mathrm{F}=0.1 ; p=\mathrm{NS}$ & $\mathrm{F}=7.5 ; p<0.001$ \\
\hline
\end{tabular}

The data were analyzed by a two-way ANOVA, where dose is the dose-response of the antipsychotic drug, treatment is the effects of vehicle or PCP administration on the behavior and dose $\times$ treatment is the interaction between the antipsychotic drug and the vehicle-PCP treatment. The table indicates degrees of freedom ( $d \mathrm{f})$, F-values, and level of significance for each behavioral parameter.

However, after a pretreatment time of $22-24 \mathrm{~h}$ haloperidol did not affect the behavior of the vehicle-treated rats, but induced a dose-dependent increase in the locomotor activity of the AMPH-treated rats (dose: $\mathrm{F}(2,66)=5.3$; $p<.01$; treatment $\mathrm{F}(1,66)=192.2 ; p<.001$; dose $\times$ treatment $\mathrm{F}(2,66)=0.2 ; p=\mathrm{NS})$.

\section{A. 3 days of administration}
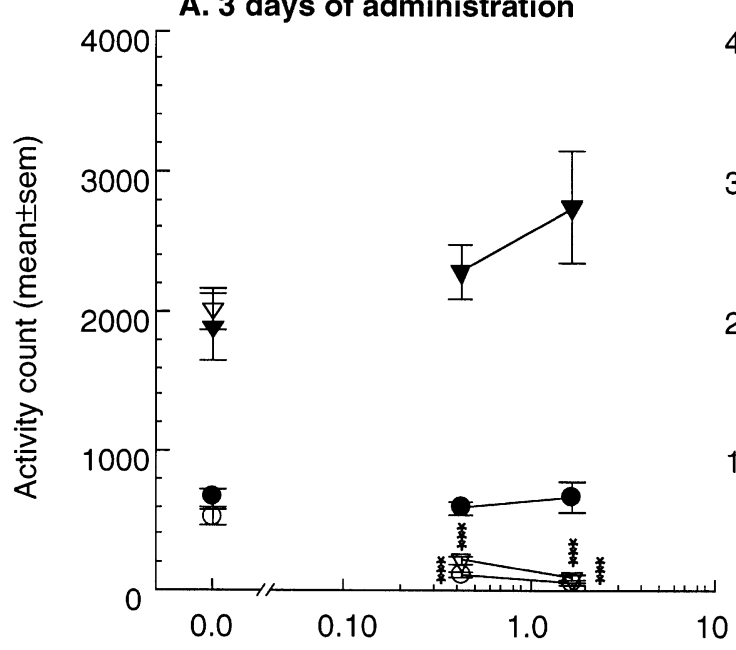

Short-term administration of clozapine (1.9 and $7.6 \mu \mathrm{mol} / \mathrm{kg} ; 0.63$ and $2.5 \mathrm{mg} / \mathrm{kg}$ ) (Figure 6A) with a pretreatment time of $30 \mathrm{~min}$ for clozapine produced a significant reduction in the locomotor activity of the vehicle-treated rats at $1.9 \mu \mathrm{mol} / \mathrm{kg}$ of clozapine and at both doses in the AMPH-treated rats (dose: $\mathrm{F}(2,72)=30.2 ; p<$

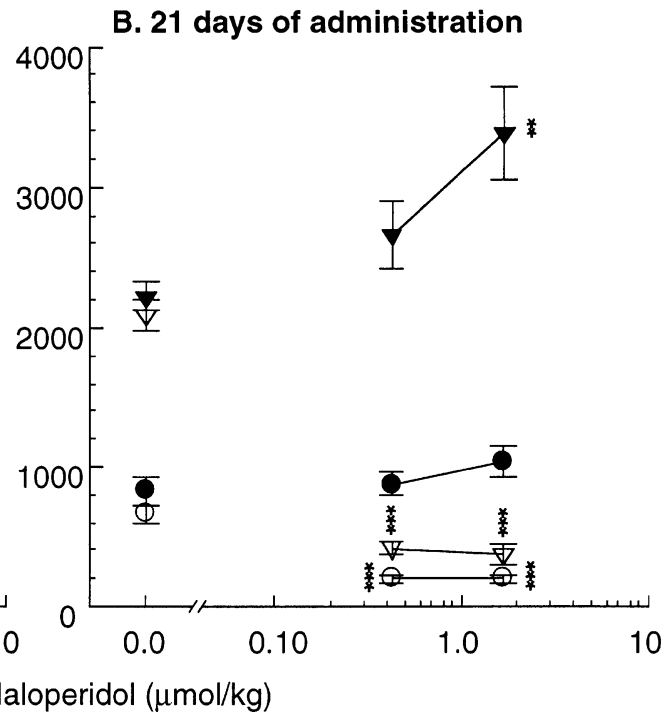

Figure 5. Dose-response of haloperidol following daily SC treatment for 3 or 21 days in combination with either vehicle or $2.7 \mu \mathrm{mol} / \mathrm{kg}$ of $\mathrm{d}$-amphetamine during the final 3 days of the haloperidol treatment regime. The rats were tested in motility cages for $2 \mathrm{~h}$ and the pretreatment time was $30 \mathrm{~min}$ or $22-24 \mathrm{~h}$ for haloperidol and $0 \mathrm{~min}$ for d-amphetamine. Each treatment group includes 12 rats, except for the highest dose of haloperidol $(n=6)$. Symbols: $(\bigcirc)$ Haloperidol in combination with vehicle; $(\nabla)$ Haloperidol in combination with $2.7 \mu \mathrm{mol} / \mathrm{kg}$ of d-amphetamine; Open symbols: Pretreatment time 30 min for haloperidol; Filled symbols: Pretreatment time 22-24 h for haloperidol. See Figure 1 for explanation of asterisks. 


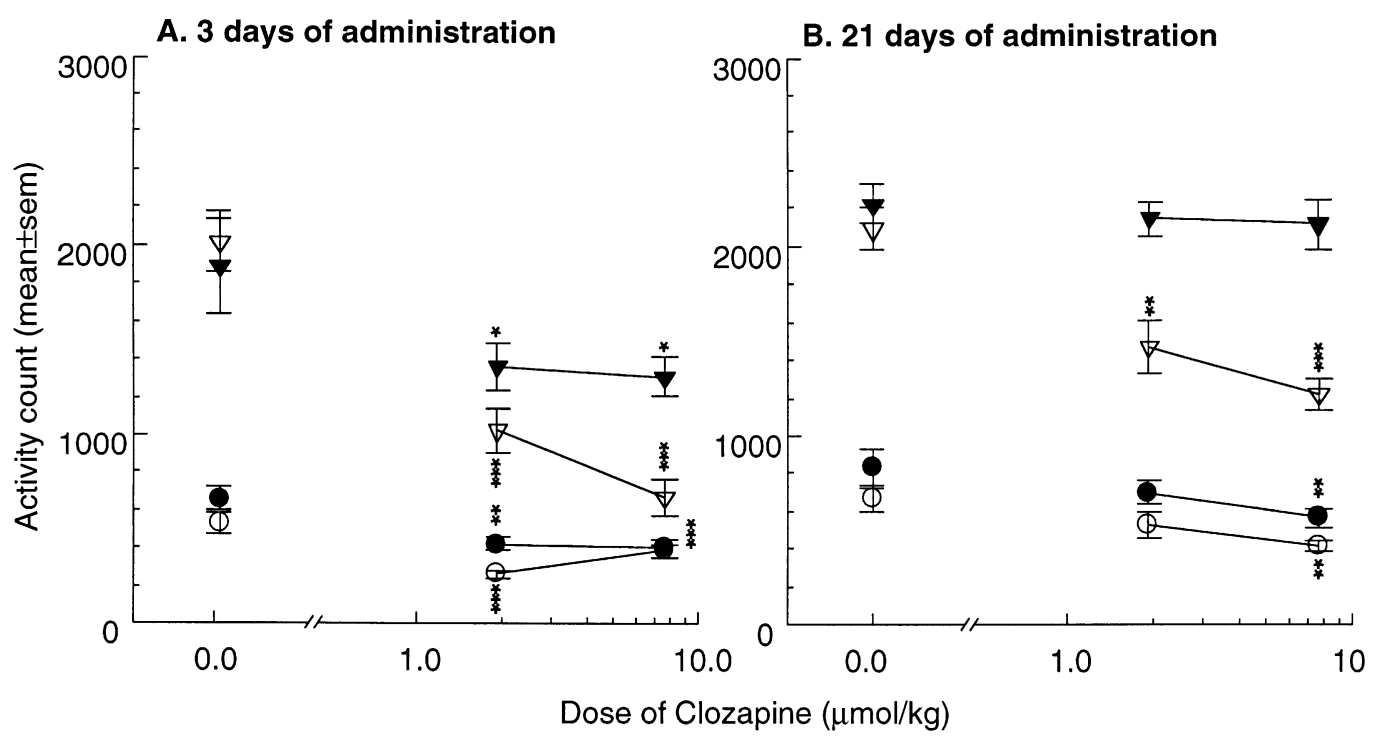

Figure 6. Dose-response of clozapine following daily SC treatment for 3 or 21 days in combination with either vehicle or $2.7 \mu \mathrm{mol} / \mathrm{kg}$ of $\mathrm{d}$-amphetamine during the final 3 days of the clozapine treatment regime. The rats were tested in motility cages for $2 \mathrm{~h}$ and the pretreatment time was $30 \mathrm{~min}$ or 22-24 h for clozapine and $0 \mathrm{~min}$ for d-amphetamine. Each treatment group includes 12 rats. Symbols: $(\bigcirc)$ Clozapine in combination with vehicle; $(\nabla)$ Clozapine in combination with $2.7 \mu \mathrm{mol} / \mathrm{kg}$ of d-amphetamine; Open symbols: Pretreatment time $30 \mathrm{~min}$ for clozapine; Filled symbols: Pretreatment time $22-24 \mathrm{~h}$ for clozapine. See Figure 1 for explanation of asterisks.

.001 ; treatment $\mathrm{F}(1,72)=140.9 ; p<.001$; dose $\times$ treatment $\mathrm{F}(2,72)=10.1 ; p<.001)$. At the long pretreatment time both doses of clozapine reduced the activity of the vehicle- and AMPH-treated rats slightly (dose: $\mathrm{F}(2,69)=$ $11.5 ; p<.001$; treatment $\mathrm{F}(1,69)=213.4 ; p<.001$; dose $\times$ treatment $\mathrm{F}(2,69)=0.5 ; p=\mathrm{NS})$. After long-term administration (Figure 6B) clozapine at the short pretreatment time produced a slight, but significant reduction at $7.6 \mu \mathrm{mol} / \mathrm{kg}$ in the locomotor activity of the vehicletreated rats and a strong reduction in the $\mathrm{AMPH}-$ treated rats at both doses tested (dose: $\mathrm{F}(2,66)=14.2$; $p<.001$; treatment $\mathrm{F}(1,66)=215.4 ; p<.001$; dose $\times$ treatment $\mathrm{F}(2,66)=0.5 ; p=\mathrm{NS})$. At a pretreatment time of 22-24 h clozapine produced a slight reduction in the activity of the vehicle-treated rats at $7.6 \mu$ mole $/ \mathrm{kg}$, but did not affect the behavior of the AMPH-treated rats (dose: $\mathrm{F}(2,66)=2.6 ; p=\mathrm{NS}$; treatment $\mathrm{F}(1,66)=301.8$; $p<.001$; dose $\times$ treatment $\mathrm{F}(2,66)=1.4 ; p=\mathrm{NS})$.

\section{DISCUSSION}

The effects of short- and long-term administration of haloperidol and clozapine in combination with PCP using a pretreatment time of $45 \mathrm{~min}$ for both compounds have previously been published for the social interaction test (Sams-Dodd 1996). Briefly described it was found that haloperidol dose-dependently suppressed the locomotor activity, per cent time in central zone and the stereotyped behavior of the vehicle- and the PCP- treated rats after both 3 and 21 days of administration, and that it did not alleviate the PCP-induced social isolation. Clozapine following 3 days of administration likewise produced a dose-dependent suppression of locomotor activity, percent time in central zone and stereotyped behavior in both the vehicle- and the PCPtreated rats, and induced deficits in the social interaction of the vehicle-treated rats without normalizing the deficits in the PCP-treated rats. Following long-term administration of clozapine the vehicle-treated rats developed tolerance to the inhibitory effects of clozapine on locomotor activity and this was now only slightly reduced at the highest dose; however, dose-dependent reductions in percent time in central zone and social interaction still occurred. In the PCP-treated rats, clozapine normalized the locomotor activity and produced a partial alleviation of the stereotyped behavior and social isolation thus demonstrating a specific effect on these parameters although clozapine did not normalize percent time in central zone.

In the present study, the effects of haloperidol and clozapine were tested in the social interaction test using a pretreatment time of 22-24 h. Both drugs had only a slight effect on the behavior of the vehicle-treated rats after 3 and 21 days of administration, indicating that drug levels in plasma must be reasonably low at this time point. It should therefore at this time point be possible to determine any specific long-term effects of haloperidol and clozapine treatment on the PCP-induced behaviors. In the PCP-treated rats haloperidol after 3 and 21 days of 
administration reduced the locomotor hyperactivity, but did not alleviate the PCP-induced stereotyped behavior or social isolation, which are the key effect parameters for this model. Clozapine also reduced the locomotor hyperactivity after 3 days of administration, but this effect disappeared after 21 days, suggesting that the rats developed tolerance to the sedative effects of clozapine. Like haloperidol, clozapine did not alleviate the PCP-induced stereotyped behavior or social isolation after 3 or 21 days of administration, except for a dose of $0.5 \mu \mathrm{mol} / \mathrm{kg}$ where clozapine significantly reduces the PCP-induced stereotyped behavior after long-term administration. The effects of clozapine on PCP-induced behaviors that previously have been described could therefore not be replicated with this long pretreatment time.

In the motility test, haloperidol and clozapine at the short pretreatment time inhibited the locomotor activity of both vehicle- and AMPH-treated rats after both 3 and 21 days of administration, which is comparable to previously published findings (e.g., Robinson and Becker 1986; Jackson et al. 1994; Arnt 1995). At the long pretreatment time, haloperidol did not affect the vehicletreated rats, but rather potentiated the AMPH-induced hyperactivity after 3 and 21 days of administration. This supersensitivity following withdrawal of haloperidol medication has previously been reported in animals by Burt et al. (1977), and Nyberg et al. (1995) have seen similar effects in man, where PET studies of the $\mathrm{D}_{2}$ receptor have shown an increase in dopamine $\mathrm{D}_{2}$-receptor density 2 weeks after withdrawal from sulpiride medication. Clozapine after 3 days of administration at the long pretreatment time inhibited the behavior of both vehicle- and AMPH-treated rats, whereas after 21 days of administration the rats developed tolerance to the effects of clozapine and it now only produced a slight reduction in the vehicle-treated rats at the highest dose and did not affect the AMPH-induced locomotor activity.

The present data have therefore shown: (1) that active levels of antipsychotic drug were present in the rats after a pretreatment time of 22-24 h, although these levels were low and only had limited effects on the vehicle-treated rats, which correspond well with the short half-lives of haloperidol and clozapine in the rat; (2) that short- and long-term administration of haloperidol and clozapine reduced the PCP- and AMPH-induced behaviors at the short pretreatment time, but that both drugs also affected the behavior of vehicle-treated rats; and (3) that short- and long-term administration of haloperidol and clozapine did not at a pretreatment time of 22-24 h consistently alleviate the PCP- or AMPHinduced behaviors. The doses used in the present study for haloperidol and clozapine are well within the range where long-term effects have been observed in rats (e.g., Skarsfeldt 1992; Sams-Dodd 1996) and are comparable to clinical doses (e.g., Breier et al. 1994). These results thus indicate that haloperidol and clozapine in these behavioral models in rats are only effective in reducing PCP- and AMPH-induced behaviors when they are given with a short pretreatment time and when reasonably high drug levels are present in plasma.

Predictive validity refers to the selectivity whereby an animal model responds to specific classes of compounds, e.g., antipsychotics or antidepressants (Willner 1984; Ellenbroek and Cools 1990). For animal models of schizophrenia based on PCP or AMPH several studies have shown that these models respond specifically to haloperidol and clozapine compared to other classes of drugs, e.g., antidepressants or anxiolytics, following acute or subchronic administration (Jackson et al. 1994; Sams-Dodd 1996). This demonstrates that these models are predictive in terms of identifying compounds that in some aspects are similar to haloperidol or clozapine. This can be referred to as limited predictive validity, because the validity is limited to particular classes of compounds. The purpose of the present set of experiments was to determine whether animal models of schizophrenia based on PCP or AMPH also can measure the underlying neurochemical changes that are directly responsible for the antipsychotic effect, a level of validity that may be referred to as full predictive validity. This type of model allows the identification of novel classes of antipsychotic compounds that may have a completely different mode of action than known antipsychotics. To test this an approach was used that is based on the clinical observations that the antipsychotic effect in schizophrenic patients has a slow onset and that the time to relapse following abrupt withdrawal of medication for most patients can be quite prolonged. In terms of an animal model this would mean the effects of antipsychotic drug treatment should demonstrate a comparable temporal pattern and therefore that rats after 21 days of treatment with haloperidol or clozapine should show a diminished response to PCP or AMPH at $24 \mathrm{~h}$ after the last administration of haloperidol or clozapine. The experiments showed that PCP in the social interaction test and AMPH in locomotor activity cages could not measure any long-term effect of antipsychotic drug treatment on the central nervous system, and these animal models therefore appear only to have limited predictive validity. It is possible that PCP and AMPH models the subgroup of patients, which shows a close correlation between plasma level of clozapine and psychopathology. This would correspond well with the observed effects of clozapine on PCP- and AMPHinduced behaviors when a short pretreatment time is used and the loss of the antipsychotic effects within $24 \mathrm{~h}$ due to the short half-life of clozapine in the rat. However, this correlation is based on a negative result and a simpler explanation would be that the interactions observed between the antipsychotic drugs and PCP and $\mathrm{AMPH}$ represent simple drug interactions. This is supported by several animal studies which have reported 
that antipsychotics can acutely reduce PCP- and AMPHinduced behaviors in various species, and in humans it has been reported that haloperidol within $1 \mathrm{~h}$ can almost completely alleviate an AMPH psychosis (Angist et al. 1974) and that haloperidol, chlorpromazin, diazepam, and phygostigmine can acutely reduce some symptoms of a PCP psychosis (Castellani et al. 1982; Giannini et al. 1985; Leikin et al. 1989).

To conclude, the present study has used a new drug administration regime to distinguish between the antipsychotic effects of haloperidol and clozapine and the drug-induced side effects to test the predictive validity of animal models of schizophrenia based on PCP and $\mathrm{AMPH}$. The study found that PCP- and AMPH-induced behavioral disturbances in rats tested in the social interaction test or in activity cages could not measure the antipsychotic effect of haloperidol and clozapine. These findings suggest that the interactions seen between $\mathrm{PCP}, \mathrm{AMPH}$, and antipsychotic drugs represent simple acute drug-drug interactions, but this needs to be confirmed in other behavioral models, e.g., the prepulse inhibition startle response (Geyer et al. 1990), and perhaps even in another species. Previous studies have shown that PCP- and AMPH-induced symptoms in humans and animals respond fairly selectively to antipsychotic drugs compared with other classes of compounds, and these models clearly can be used for distinguishing between classes of antipsychotic drugs and perhaps their effect on different types of clinical symptoms. However, the present study suggests that animal models of schizophrenia based on PCP and AMPH cannot measure the long-term neurochemical effects of antipsychotic drug treatment that are believed to be related to their antipsychotic properties, and therefore that these models lack full predictive validity.

\section{ACKNOWLEDGMENTS}

I thank Ms. Marit Pedholt Larsen and Ms. Pi Ørum for technical assistance in conducting these experiments, and Dr. Jørn Arnt and Mrs. Jeanette Sams-Dodd for comments.

\section{REFERENCES}

Angist B, Lee HK, Gershon S (1974): The antagonism of amphetamine-induced symptomatology by a neuroleptic. Am J Psychiatry 131:817-819

Arnt J (1995): Differential effects of classical and newer antipsychotics on the hypermotility induced by two levels of D-amphetamine. Eur J Pharmacol 283:55-62

Baldessarini RJ, Centorrino F, Flood JG, Volpicelli SA, Huston-Lyon D, Cohen BM (1993): Tissue concentrations of clozapine and its metabolites in the rat. Psychopharmacology 9:117-124

Borison RL, Diamond BI, Sinha D, Gupta RP, Ajiboye PA
(1988): Clozapine withdrawal rebound psychosis. Psychopharmacol Bull 24:260-263.

Breier A, Buchanan RW, Kirkpatrick B, Davis OR, Irish D, Summerfelt A, Carpenter WT (1994): Effects of clozapine on positive and negative symptoms in outpatients with schizophrenia. Am J Psychiatry 151:20-26

Bunny BS, Grace AA (1978): Acute and chronic haloperidol treatment: Comparison of effects on nigral dopaminergic cell activity. Life Sci 23:1715-1728

Burt D, Creese I, Snyder S (1977): Antischizophrenic drugs: Chronic treatment elevated dopamine receptor binding in brain. Science 196:326-328

Castellani S, Adams PM (1981): Acute and chronic phencyclidine effects on locomotor activity, stereotypy and ataxia in rats. Eur J Pharmacol 73:143-154

Castellani S, Giannini AJ, Boeringa JA, Adams PM (1982): Phencyclidine intoxication: Assessment of possible antidotes. J Toxicol Clin Toxicol 19:313-319

Cheng YF, Paalzow LK (1992): Linear pharmacokinetics of haloperidol in the rat. Biopharm Drug Dispos 13:69-76

Connell PH (1958): Amphetamine Psychosis. London, Chapman \& Hall

Ellenbroek BA, Cools AR (1990): Animal models with construct validity for schizophrenia. Behav Pharmacol 1: 469-490

File SE (1980): The use of social interaction as a method for detecting anxiolytic activity of chlordiazepoxide-like drugs. J Neurosci Methods 2:219-238

Freed WJ (1988): The therapeutic latency of neuroleptic drugs and nonspecific postjunctional supersensitivity. Schizophr Bull 14:269-277.

Geyer M, Swerdlow NR, Mansbach RS, Braff DL (1990): Startle response models of sensorimotor gating and habituation deficits in schizophrenia. Brain Res Bull 25:485-498

Giannini AJ, Loiselle RH, Price WA, Giannini MC (1985): Chlorpromazine vs. meperidine in the treatment of phencyclidine psychosis. J Clin Psychiatry 46:52-54

Huitema BE (1980): The Analysis of Covariants and Alternatives. New York, Wiley \& Sons

Jackson DM, Johansson C, Lindgren LM, Bengtson A (1994): Dopamine receptor antagonists block amphetamine and phencyclidine-induced motor stimulation in rats. Pharmacol Biochem Behav 41:465-471

Jann MW, Grimsley SR, Gray EC, Chang WH (1993): Pharmacokinetics and pharmacodynamics of clozapine. Clin Pharmacokinet 24:161-176

Khot V, DeVane CL, Korpi ER, Venable D, Bigelow LB, Wyatt RJ, Kirch DG (1993): The assessment and clinical implications of haloperidol acute-dose, steady-state, and withdrawal pharmacokinetics. J Clin Psychopharmacol 13:120-127

Leikin JB, Krantz AJ, Zell-Kanter M, Barkin RL, Hryhorczuk DO (1989): Clinical features and management of intoxication due to hallucinogenic drugs. Med Toxicol Adverse Drug Exp 4:324-350

Lin SK, Chang WH, Chung MC, Lam YW, Jann MW (1994): Disposition of clozapine and desmethylclozapine in schizophrenic patients. J Clin Pharmacol 34:318-324

Murray TF, Horita A (1979): Phencyclidine-induced stereotyped behavior in rats: Dose response effects and antagonism by neuroleptics. Life Sci 24:2217-2226 
Nyberg S, Nordström A-L, Halldin C, Farde L (1995): Position emission tomography studies on D2 dopamine receptor occupancy and plasma antipsychotic drug levels in man. Int Clin Psychopharmacol 10:81-85

Robinson TE, Becker JB (1986): Enduring changes in brain and behavior produced by chronic amphetamine administration: A review and evaluation of animal models of amphetamine psychosis. Brain Res Rev 11: 157-198

Sams-Dodd F (1995a): Distinct effects of d-amphetamine and phencyclidine on the social behaviour of rats. Behav Pharmacol 6:55-65

Sams-Dodd F (1995b): Automation of the social interaction test by a video tracking system: Behavioural effects of repeated phencyclidine treatment. J Neurosci Methods 59:157-168

Sams-Dodd F (1996): Phencyclidine-induced stereotyped behaviour and social isolation in the rat: A possible animal model of schizophrenia. Behav Pharmacol 7:3-23

Sams-Dodd F (1997): Effect of novel antipsychotic drugs on PCP-induced stereotyped behaviour and social isolation in the rat social interaction test. Behav Pharmacol 8:196-215
Siegel RK (1978): Phencyclidine and ketamine intoxication a study of 4 populations of recreational users. In Peterson RC, Stillman RC (eds), National Institute of Drug Abuse Research Monograph \#21. Washington, DC, NIH Press, pp 119-147

Skarsfeldt T (1992): Electrophysiological profile of the new atypical neuroleptic, sertindole, on midbrain dopamine neurones in rats: Acute and repeated treatment. Synapse 10:25-33

Vahid-Ansari F, Nakabeppu Y, Robertson GS (1996): Contrasting effects of chronic clozapine, seroquel, and haloperidol administration on FosB-like immunoreactivity in the rodent forebrain. Eur J Neurosci 8:927-936

Viguera AC, Baldessarini RJ, Hegarty JD, van Kammen DP, Tohen M (1997): Clinical risk following abrupt and gradual withdrawal of maintenance neuroleptic treatment. Arch Gen Psychiatry 54:49-55

Willner P (1984): The validity of animal models of depression. Psychopharmacology 83:1-16 